See discussions, stats, and author profiles for this publication at: https://www.researchgate.net/publication/273674549

\title{
Identification and Separation of Lead (II), Nickel (II), and Cobalt (II) on Silica Gel 60 F-254 High-Performance Thin-Layer Chromatographic Plates with Mixed Aqueous Sodium Dodecyl...
}

Article in JPC - Journal of Planar Chromatography - Modern TLC · August 2012

DOI: 10.1556/JPC.25.2012.4.13

CITATIONS

3

6 authors, including:

Showkat Bhawani

University Malaysia Sarawak

48 PUBLICATIONS 263 CITATIONS

SEE PROFILE

Mohamad Nasir Mohamad Ibrahim

Universiti Sains Malaysia

137 PUBLICATIONS 1,631 CITATIONS

SEE PROFILE

Some of the authors of this publication are also working on these related projects:

Drilling mud additives View project

Final Year Project (Resource Chemistry) View project
29 PUBLICATIONS 567 CITATIONS

SEE PROFILE

Othman Sulaiman

Universiti Sains Malaysia

334 PUBLICATIONS 6,232 CITATIONS

SEE PROFILE 


\title{
Identification and Separation of Lead (II), Nickel (II), and Cobalt (II) on Silica Gel $60 \mathrm{~F}_{254}$ High-Performance Thin-Layer Chromatographic Plates with Mixed Aqueous Sodium Dodecyl Sulfate-Oxalic Acid Solvent System
}

\author{
Showkat A. Bhawani, Sufia Hena, Mohamad N. Mohamad Ibrahim, Othman Sulaiman, Rokiah Hashim, and Kok L. San
}

Key Words

Separation

High-performance thin-layer chromatography

Lead (II)

Nickel (II)

Cobalt (II)

\section{Summary}

The chromatographic separation of three metal cations was performed on high-performance thin-layer plates (silica gel $60 \mathrm{~F}_{254}$ ) with mixed sodium dodecyl sulphate (SDS) and oxalic acid. The effect of concentration of surfactant and additive effect of different carboxylic acids on the mobility of metal ions were investigated. The resolution of a mixture of $\mathrm{Pb}^{2+}, \mathrm{Ni}^{2+}$, and $\mathrm{Co}^{2+}$ was achieved by using $0.2 \mathrm{M}$ SDS plus $0.08 \mathrm{M}$ oxalic acid, $1: 9, v / v$ as a solvent system. The developed method was utilized to identify these metal ions in different spiked water samples after their preliminary separation.

\section{Introduction}

Thin-layer chromatography (TLC) continues to be an important method for qualitative analysis of metal ions because of its inherent advantages - many samples can be analyzed simultaneously and quickly, use of specific and colorful reactions and easier manipulation of stationary and mobile phases, and highly effective separation technique for analyzing complex mixtures into individual components. On the other hand, the use of surfactants in thin-layer chromatography has expanded the potentialities of the technique. Surfactants are capable to resolve the mixtures of both neutral and charged compounds. Surfactants are generally used above the micellar concentration as a solvent system. Micellar thin-layer chromatography has some advantages and has gained immense popularity because of operational simplicity, cost effectiveness, relative non-toxicity, and enhanced separation efficiency $[1,2]$. The efficiency of this method is very high because the solubilizaton of mixture components with micelles is caused by the fact that the micelle-sorbate interaction involves a complex of electrostatic, hydrophobic, donor-acceptor and polarization interactions [3-5]. Litera-

S.A. Bhawani and M.N. Mohamad Ibrahim, School of Chemical Sciences, Universiti Sains Malaysia, 11800, Pulau Pinang, Malaysia; S. Hena, O. Sulaiman, R. Hashim, and K.L. San, School of Industrial Technology, Universiti Sains Malaysia, Pulau Pinang, Malaysia.

E-mail: sabhawani@gmail.com ture reveals [6-8] that sodium dodecyl sulphate (SDS) has been used in the separation of metal ions and has provided potential chromatographic systems for the resolution of complex mixtures of metal ions. A number of analytical methods have been developed for the separation of $\mathrm{Ni}$ and $\mathrm{Co}$ [9-11]. Most of the methods are expensive, involve lengthy sample preparation steps, require large volume of sample, and most important is the use of highly toxic chemicals. Several thin-layer chromatographic methods have been developed for the analysis of metal ions [12-17]. The proposed novel combination of $0.2 \mathrm{M}$ sodium dodecyl sulphate (SDS) plus $0.08 \mathrm{M}$ oxalic acid, 1:9, $v / v$ successfully resolved the mixture of metal ions such $\mathrm{Pb}^{2+}, \mathrm{Ni}^{2+}$, and $\mathrm{Co}^{2+}$ and is not available in the literature. Furthermore, the proposed method is capable to identify these metal ions present in different water samples.

\section{Experimental}

All experiments were performed at $25 \pm 2{ }^{\circ} \mathrm{C}$.

\subsection{Chemical and Reagents}

Silica gel $60 \mathrm{~F}_{254}(1.05548)$ HPTLC aluminum foils (Merck, Darmstadt, Germany), sodium dodecyl sulphate (Merck, Darmstadt, Germany), formic acid, acetic acid, oxalic acid, dithizone, dimethyglyoxime, carbon tetrachloride $\left(\mathrm{CCl}_{4}\right)$, and ethanol were used. All the reagents were of analytical grade.

\subsection{Metal lons Studied}

Nickel chloride $\left(\mathrm{NiCl}_{2}\right)$, cobalt chloride $\left(\mathrm{CoCl}_{2}\right)$, and lead nitrate $\left(\mathrm{Pb}\left(\mathrm{NO}_{3}\right)_{2}\right)$ were purchased from Sigma-Aldrich, Chemie $\mathrm{GmbH}$, Steinheim, Germany. All metal ions were used as received.

\subsection{Test Solutions}

All the test solution were prepared in distilled water and contained $1.0 \%(w / v)$ aqueous solution of chlorides of $\mathrm{Ni}^{2+}$ and $\mathrm{Co}^{2+}$ and nitrate of $\mathrm{Pb}^{2+}$. 